\title{
A VARIATIONAL PROOF OF BIRKHOFF'S THEOREM ON DOUBLY STOCHASTIC MATRICES
}

\author{
QIJI J. ZHU
}

Abstract. This note provides a short variational proof of the Birkhoff's theorem asserting that the extreme points of the convex set of doubly stochastic matrices are the permutation matrices.

Mathematics subject classification (2000): 15A42, 15A51, 58E30.

Key words and phrases: Variational method, doubly stochastic matrix, majorization, Birkhoff theorem.

\section{REFERENCES}

[1] T. ANDO, Majorization, doubly stochastic matrices and comparison of eigenvalues, Linear Algebra and Its Applications, 118 (1989) 163-248.

[2] R. BHATIA, Matrix Analysis. Springer-Verlag, New York, 1997.

[3] J. M. BoRWEIN AND A. S. LEWIS, Convex Analysis and Nonlinear Optimization: Theory and Examples, Springer, New York, 2000.

[4] J. M. BorWEIN, A. S. LeWIS, AND R. NussBaum, Entropy minimization, DAD problems and doublystochastic kernels, Journal of Functional Analysis, 123 (1994), 264-307.

[5] J. M. BORWEIN AND D. PREISS, A smooth variational principle with applications to subdifferentiability and to differentiability of convex functions, Trans. Amer. Math. Soc., 303 (1987), 517-527.

[6] I. EKELAND, On the variational principle, J. Math. Anal. Appl., 47 (1974), 324-353.

7] R. A. Horn And C. R. Johnson, Topics in Matrix Analysis, Cambridge University Press, Cambridge, 1991. 